\title{
Interactive Visual Music
}

\author{
Julie Watkins \\ University of Greenwich \\ Stockwell Street, London, \\ SE10 9LS, UK \\ j.watkins@gre.ac.uk
}

\begin{abstract}
How can Visual Music be composed and presented in such an engaging way that it will turn spectators into participants? How to connect a youthful, twenty-first century audience who are keen to update their Instagram story with Visual Music? Visual Music is an art form, which is "an equal and meaningful synthesis of the visible and audible" (Lund \& Lund 2009, p.149) and "is typically non-narrative and non-representational" (Evans 2005, p.11). Visual Music is often presented as cinema. Cinema audiences are generally considered to be passive spectators, whose "reactions are pre-programmed by the director, crew, cast and writer" (Mackintosh 2003, p.2). This paper highlights the nexus between, to use McCall's (2004) terms 'the cinematic, the sculptural and the pictorial', with a focus on creating interactive Visual Music installations.
\end{abstract}

Visual music. Animation. Human traces. Light. Interactive. Embodied. Installation.

\section{INTRODUCTION}

Light has long been animated in performances of visual music, in projected light shows and works, and used to create, in James Turrell's term, 'sensing spaces' (Adcock \& Turrell 1990, p.111). To expand the experience created by my visual music pieces I moved from fixed-screen-based work to creating an interactive piece in the medium of light that invites spectator-participants to walk through it, to be inside it and to react to it.

\section{DEVELOPING SINGING LIGHT 1}

In Singing Light 1 the spectator-participants walk through an-architecture-of-light-with-sound from an unseen singer. Each experience is individual and unique. The piece creates a deep space: the projected animation is broken across long, illuminated hanging strips that recede into the space. The singing is played from speakers at each side of the room to emphasise the space. The light forms animations in the air, given volume by the ever-changing haze created by a haze machinethis effect was inspired by Anthony McCall's "solid light films" (McCall 2014). Coloured lights constantly evolve and change, softening the austerity of the monochrome light tunnels and adding more depth through colour-using evolving colours in light was inspired by Thomas Wilfred's work (Orgeman et al. 2017).

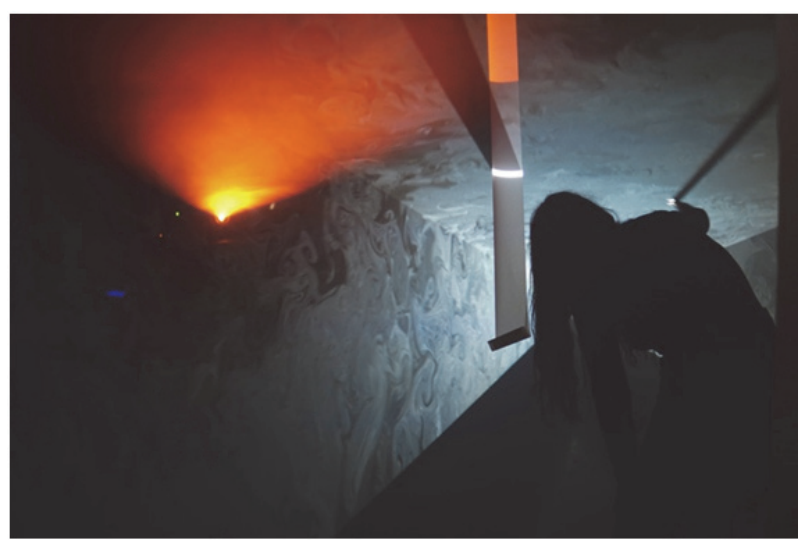

Figure 1: Singing Light 1 (Watkins 2018), from inside the volumetric light tunnel. Photo Luca Portik.

Singing Light 1 only exists when it is installed-it cannot be played on a fixed screen. I chose to install it in a TV Studio, which is essentially a large black-walled space, with completely controllable lighting. The interaction of the animation and the display directly impacted on my creative process as I developed the work. Creating the piece necessitated creating animations and experimenting with how I displayed them in the performance space. I walked around the space to absorb the full effect. I created new animations to test, developed the display with the new animations and reflected on the result. This was an iterative process over several weeks. My starting point as an animator was to imagine the singer's voice in 
the space and to create a horizon line, the fundamental line that separates sky from earth, as moving bright line, animated in space. The line will be given impetus to move by the vocal expression and tempo of the voice. The line is literally and metaphorically central to the work. This builds on my initial phenomenological explorations into proximal and distal environments. The first is where the sky meets the sea and the horizon seems limitless. The sky and the sea meet seamlessly. My whole vision is filled. The effect is of being somewhere so wide open is that I feel wide open, my eyes open wider, the top of my head feels as if it has lifted off. I breathe in the air and feel that I expand out to the limitless horizon. The second setting is under leafy branches looking down at dappled shadow. The leaves form an unseen canopy above me, the invisible wind sways the branches and the shadows slowly dance, forming and re-forming. They drape over the uneven bridle path. The patterns are subtle, soft ever evolving forms in muted colours. The patterns are everchanging and ever-engaging. I imagine being able to blow, like the wind, and see the shadows dance to my breath, and how I would feel empowered, invisible and effective. My breath would become a visible gesture. Don Ihde writes:

The invisibility of the wind is indicative. What is the wind? It belongs, with motion, to the realm of verb. The wind is "seen" in its effects, less than a verb, its visible being is what it has done in passing by. (Ihde 2007, p.51)

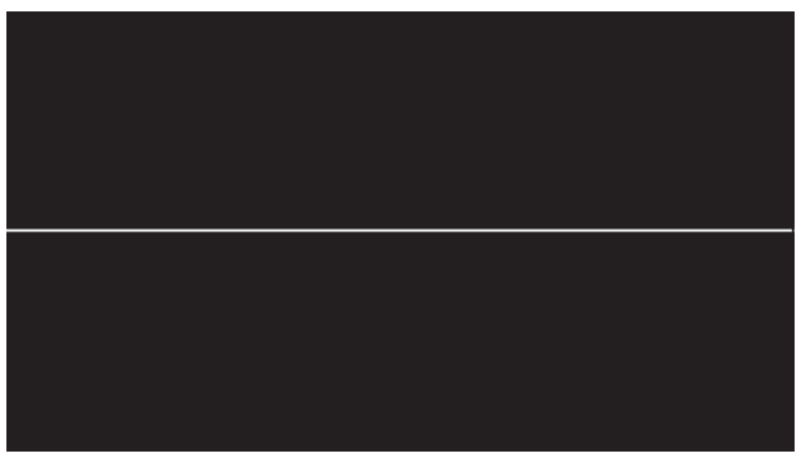

Figure 2: Projected line from Singing Light 1 (Watkins 2018).

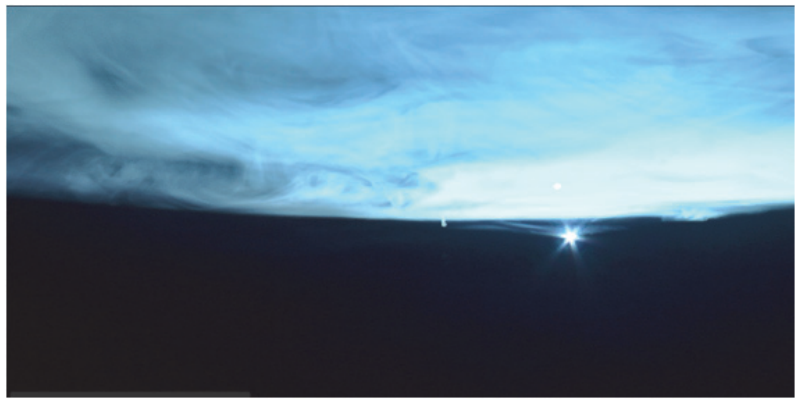

Figure 3: Looking back at the projector, Singing Light 1 (Watkins 2018).
The line is given substance by the haze, which has its own texture and density. Reflecting on the animation of geometric forms by Hans Richter, who used the cinematic frame as a movie-canvas and contrast-analogy (Richter 1952), resulted in the realisation that outside of the frame of a screen, beyond the screen, i.e. in the haze, the restriction is not bounded by the frame but by what is visible in the haze. This gave rise to developing a piece that has a flow of changing coloured light in motion and exploring volumetric light that would be impossible to create if the light were physically shaped by metal or barn-doors because the shapes fluidly evolve from one geometric form to another, i.e. they morph as only animation can.

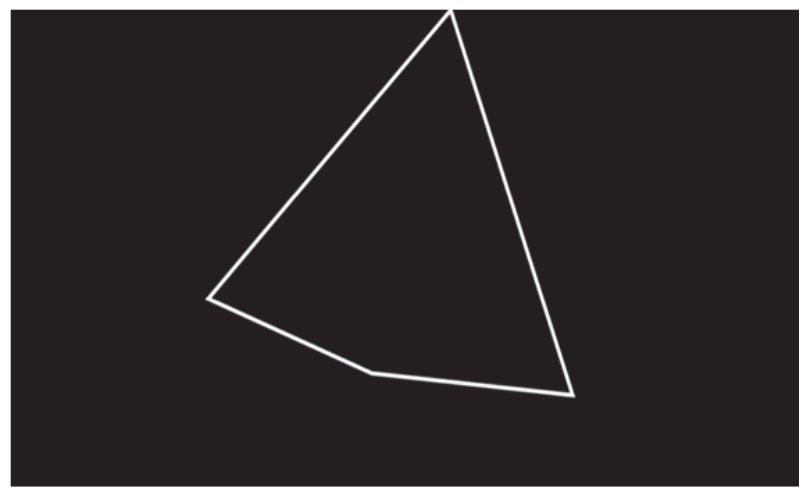

Figure 4: Singing Light 1 (Watkins 2018), a triangle fluidly morphing into a square.

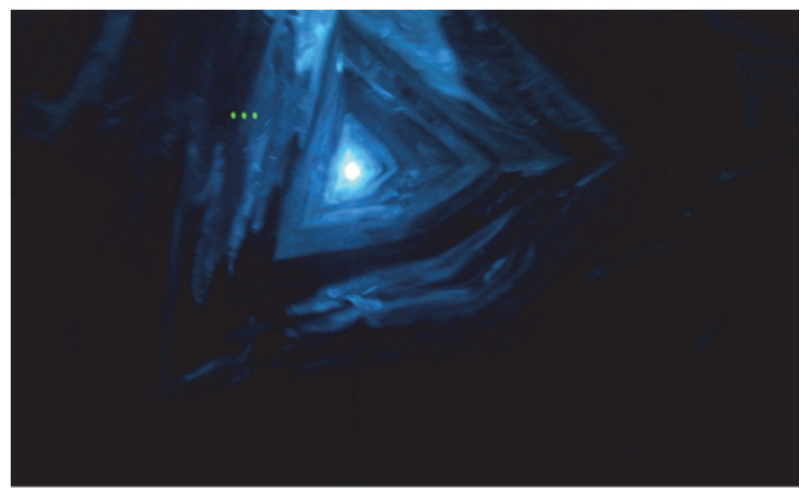

Figure 5: Singing Light 1 (Watkins 2018), triangle morph looking back at the projector through the haze.

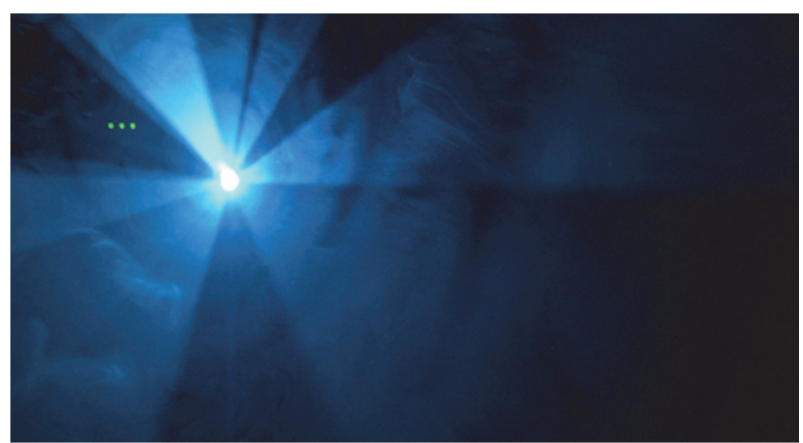

Figure 6: RingSegments (Watkins 2018), looking back at the projector through the haze. 
Additionally, referencing Paul Klee, 'dividualindividual' shapes (Klee \& Spiller 1970) were explored. Circles were divided and augmented with rotating circle segments, thus integrating hardedged linear 'dividual' elements with the smooth cone. The projection was further broken across the planes of narrow flags, spaced to create more depth (Figure 8). The power of animating light in space was key to creating abstract animation that had the potential to be affective over a sustained period.

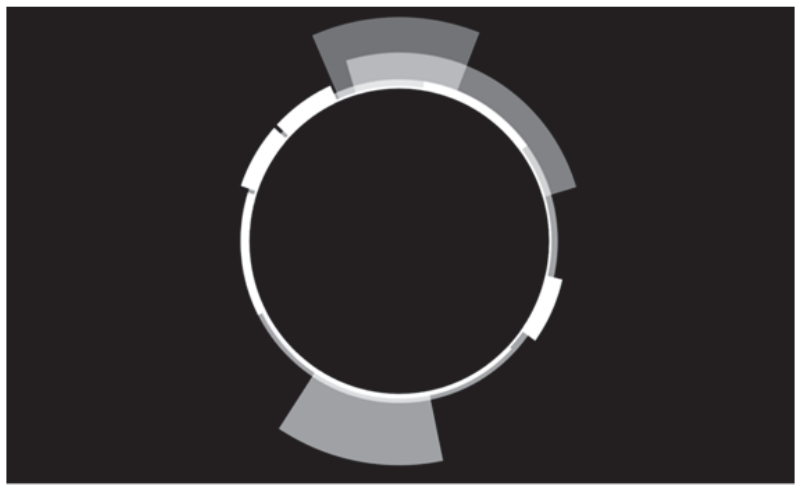

Figure 7: RingSegments (Watkins 2018), animation

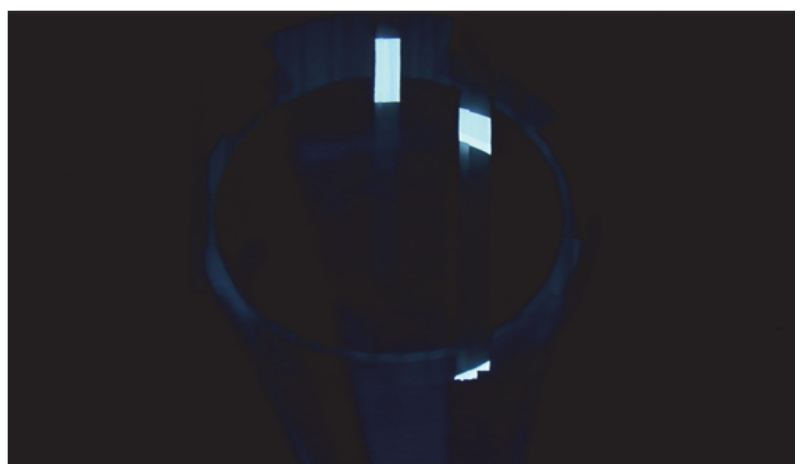

Figure 8: RingSegments (Watkins 2018), projected in the haze and highlighted by flags.

I created very slow animation to allow spectatorparticipants to move around and through the installation and give them time to react to it; for example, the six-minute-change from a horizontal line to the outline of a rectangle filling screen. The change was almost imperceptible until minutes had past; in the manner of "slow cinema" (Flanagan 2012). This slowness was emphasised through contrast with rapid sections: the rectangle quickly scaled into a vertical line over eight seconds, and then rotated to become a new horizontal line over the next eight seconds. The most rapid changes occurred over half a second. The piece was unpredictable as changes occur at irregular intervals and with irregular pacing. The aim was to evoke something more akin to being in nature and experiencing "soft fascination" (Kaplan 1992) than to seeing a performance. To this end I created a loopable, hour-long animation (Figure 9) that the beholders could walk in and out of at any moment. The line animations were designed with the knowledge that they would be emphasised with sung phonemes. I created "animated-image-audio units" (Watkins 2018) by consistently associating certain sounds with particular animations. The vocal both emphasises and creates the impetus for change; for example scale change and the drawing on or off of lines start on "ooo" (Figure 9).
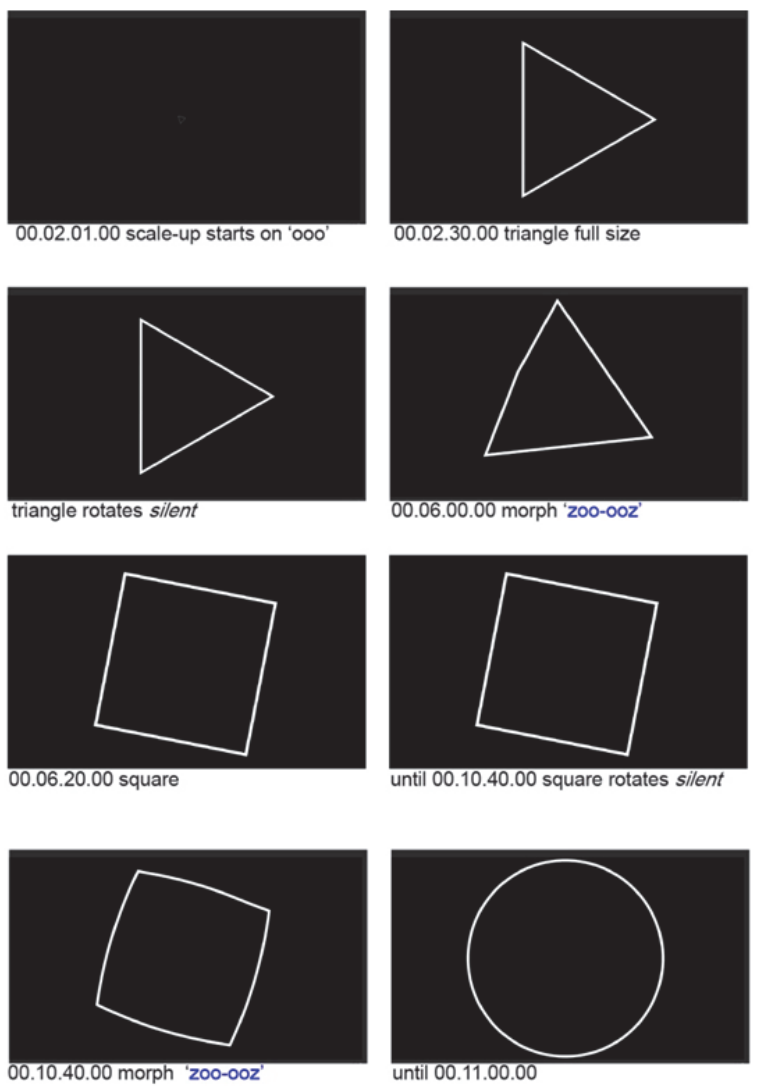

Figure 9: Keyframes from AnimatedShapes (Watkins 2018).

Some animations are back-timed to emphasise the ending point, for example a line stops rotating on the "g" of "ooog". 'Dividual' elements (Figure 13) are shaken in or out of lines on "voo-oov" which gets louder on shake out and quieter on shake back. Morphs are associated with "zoo-ooz". These sounded motions have acceleration or deceleration. Constant motion, for example slow rotation, contrasts with this and is emphasised by the movement being silent. The sonic element feels of equal weight to the visuals although the visuals are continuous and there are minutes of silence. To use Gombrich's term, the audio is "incomplete" and so gives the beholder's imagination space to respond (Gombrich 1960, p.200).

Vocal expression is key. Singing Light 1 places the voice as the primordial, affective sonic element. The voice wells up, it has presence, it is unseen, an 
"acousmetre" (Chion et al. 1994, p.71). The singer is unseen, allowing the voice to be outside the visual frame, acousmatic, in a wider frame. The "acousmetre" gives the vocal expression power and "omniscience" using non-verbal vocals avoids the associations of words and allows the perceiver to connect directly with the "virtual person" (Juslin \& Laukka 2003) within the voice. In order to create a meditative sound the singing is purposefully limited to a single voice singing a single pitch. Limiting the vocals to a very narrow range of frequencies emphasises rhythm and prosodic qualities over pitch, avoiding melodic expectations and associations. By exploring musical suspension through using a very limited pitch range melodic expectations are avoided. Creating a composition of one long shot using seamless transitions also removes the metric effect of cuts and frees the composition from allusions to musical metrical structures.

With no musical structure, no words or melody with which to create local predictions, the unpredictability of the composition is increased and wider opportunities for creating surprise are created. Singing Light 1 has the visceral surprise of the singer's voice welling up out of the darkness, giving impetus to the animated motion of the line, that, through the haze creates the physical surprise of the three-dimensionality of the tunnel of light. The unpredictability of the piece allows the beholder to oscillate between an immersive, affective engagement with the immediate scenelike a firework display-and seeing pockets that make sense because there is perception of connected events or causality or animacy or metaphor. In contrast the whole is unknowable, unpredictable, even chaotic; there is no musical or narrative structure with which to create overarching expectations of the piece. But the human traces in the vocal expression create resonances that support the use of light itself as a medium, becoming a celebration of light as a fundamental affective, embodied experience.

\section{INSTALLATION OF SINGING LIGHT 1}

I installed Singing Light 1 for SOUND/IMAGE 2018 in the same television studio at the University that I had used for developing the work. The height of the nine-metre-high walls was accentuated by the flags draping down from the gantry, (Figure 19). I used a 13,000 lumens projector on the floor to project Animated Shapes upwards against a black curtain at the back and a 3,000 lumens projector to project Volumetric Colours at an angle to this, to mix in evolving colours in the upper portion of the space (Figure 12). Placing the projections at an angle, i.e. not projecting horizontally ensured that the volumetric projections in the haze did not evoke fixed-screen projections in a cinema. Mixing colours from a second projector across the first further distanced the projections from a film. I hung six tracing paper flags to create planes of depth and thoroughly integrate the animation into real three-dimensional space. I did not weight the ends of flags but allowed them to curl and to gently sway with the breeze caused by the fan moving the haze and in response to spectator-participants brushing against them. The swaying evoked the first spark of inspiration that I had for Singing Light 1, being in the dappled shadows under trees with gently swaying branches. The soft, marbled, turbulence of the haze, the irregular curls of the flags and irregular shapes of the spectator-participants contrasted with the geometries of the animation and the linearity of the projections and cast shadows (Figure 1).

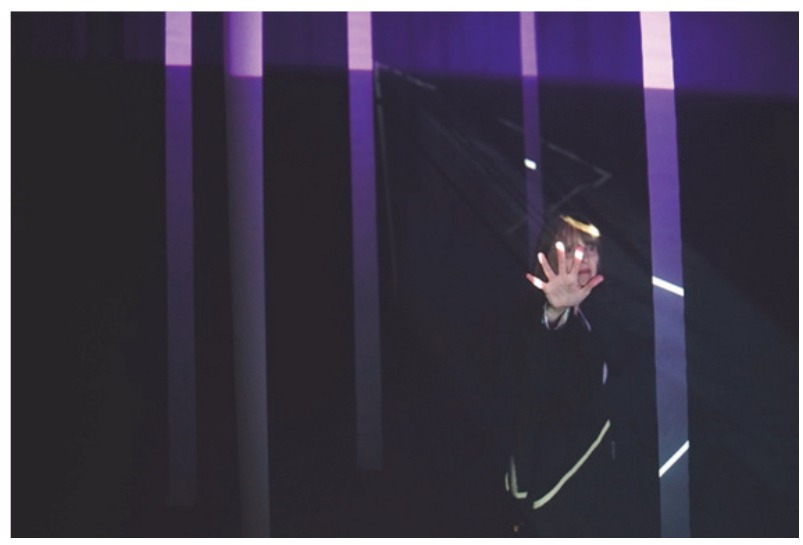

Figure 10: Interacting with Singing Light 1 (Watkins, 2018) Photo Luca Portik.

Displaying the animation less brightly on the black back curtain than on the flags (see the triangle in Figure 10) and even letting the folds of the back curtain distort the animation into more of a texture than a clean image (Figure 11) was important in creating a balance in the installation. If the backcurtain image was stronger participants tended to become spectators and fall into the fixed-screen habit of looking at the back wall. The tracing paper flags were translucent and showed the white lineas chevrons of highlights-and colour projections on from the front and back (Figure $13 \& 15$ ). This gave an equal level of intensity of imagery to spectator-participants whether they were facing the back wall or looking in the direction of the projector.

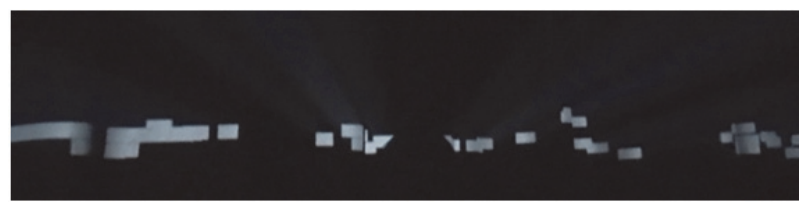

Figure 11: Animation broken by rippling over folds in the curtain Singing Light 1 (Watkins 2018). 


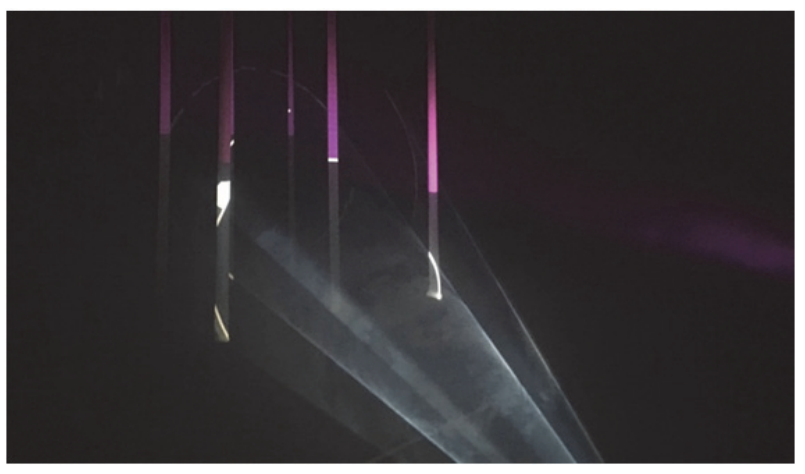

Figure 12: Concentric rings of light flags and colour projection Singing Light 1 (Watkins 2018).

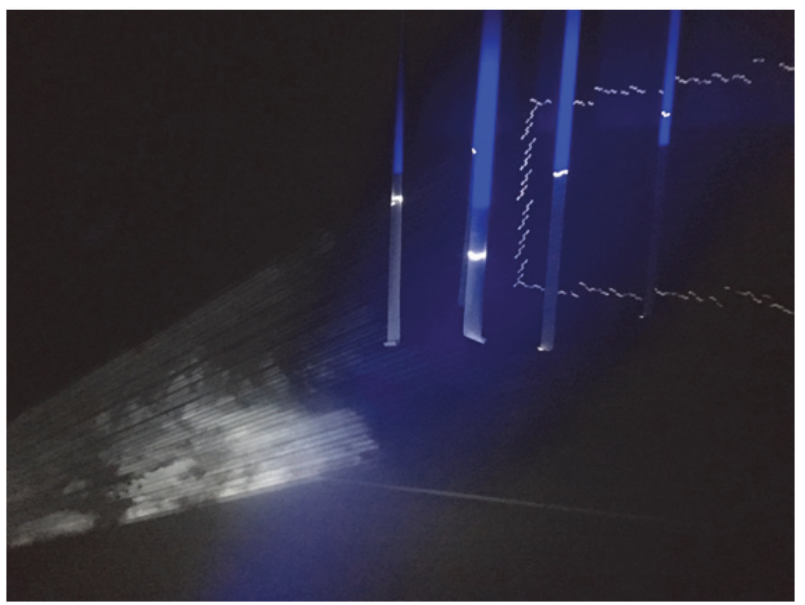

Figure 13: 'Dividual' elements animating to form a rectangle and creating a different quality of projected ray and depth in the environment, Singing Light 1 (Watkins 2018).

This careful design, that balanced the projection sources and receiving surfaces in the environment created an installation that was multi-planar with complex levels-of-depth that changed as the animation progressed (Figures 12-14).

The audio of Animated Shapes was fed through two speakers placed at either side of the room. The intermittent, meditative, acousmatic sound welled up out of the darkness from both sides enveloping the space. There were other sounds present in the environment, the fan created a continuous low hum, the haze machine gently puffed out haze every few minutes and spectator-participants talked quietly with each other, stopping when they heard

For Animated Shapes I wanted to create a quite intimate experience in which spectator-participants could explore and be playful. Therefore, it was important not to overcrowd the space. In the first thirty minutes about forty spectator-participants entered the space and the second thirty minutes about thirty more entered. The maximum number in the space at any one time was about twenty. They tended to be more still, explore less and interact less when the group was larger. Many spectator- participants stayed for between five to ten minutes. They stayed longer if they took photos and played in the light and longest if they found a spot at the side of the room in the dark from where they observed. A few stayed for about thirty minutes. The shortest visit was about one minute. The briefest visit was when a spectator-participant glanced in and the animation was creating a small blade of light. In James Turrell's terms they did not "self-select" (Guggenheim 2017) to wait and see what would happen next.

The spectator-participants journeyed through the physical space and through their evolving experience of Singing Light 1. I put tape on the floor to give the spectator-participants a safe path to follow around in the darkness. Spectatorparticipants tended to hesitate as they entered and got their bearings in the dark space and let their eyes adjust to the low light. A few groups of three or four followed each other around the line on the floor and stopped against the back wall. They stood in a huddle, watched the animated shapes and looked around the environment (Figure 15). Most of the spectator-participants exhibited surprise when they saw how the projected animation became a shape with incredible three-dimensional volume in the haze when stepping into the beam. This was demonstrated by their expressions and how they huddled together to watch the volumetric projection. I too experienced this surprise when developing Singing Light 1, the first time one steps into the beam and sees a tunnel of light has a visceral quality; it is affective. There is an element of illusion; the effect of the light is completely different looked at from outside the beam to inside the beam. Once having seen this three-dimensional volume, one's perception of the beam changes. Merleau-Ponty writes of a 'stone' which, on closer inspection resolves to be a patch of sunlight (Merleau-Ponty 2005, p.346), in this case knowing that the projection can be a tunnel of light informs subsequent perception of the projection, from whichever angle it is looked at.

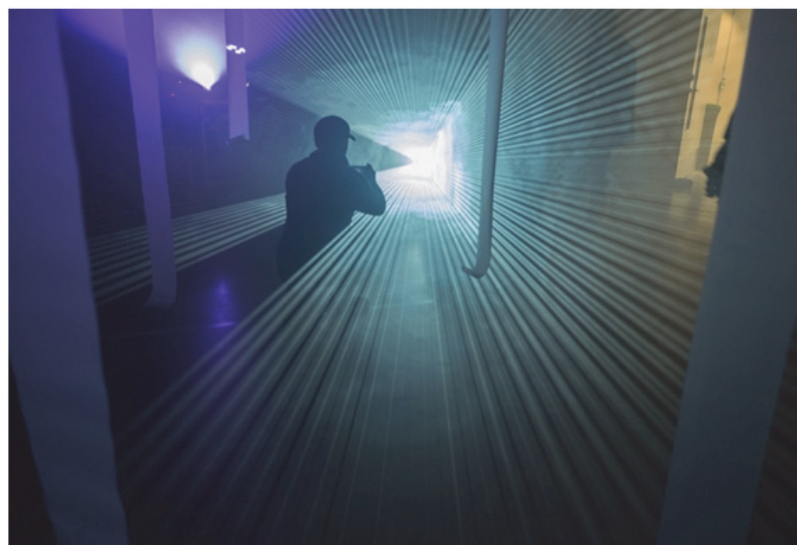

Figure 14: 'Dividual' rectangle creating rays of light, spectator-participant Singing Light 1 (Watkins 2018). 


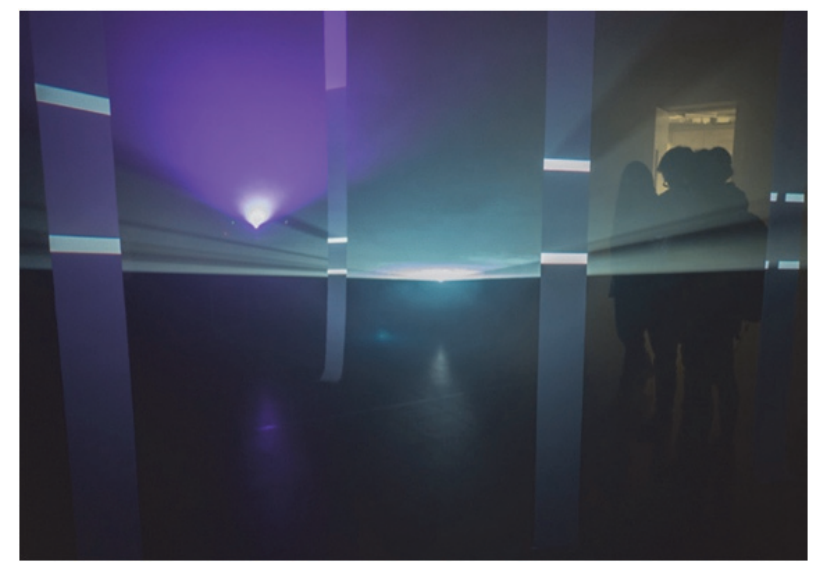

Figure 15: Spectator-participants entering Singing Light 1 (Watkins 2018).

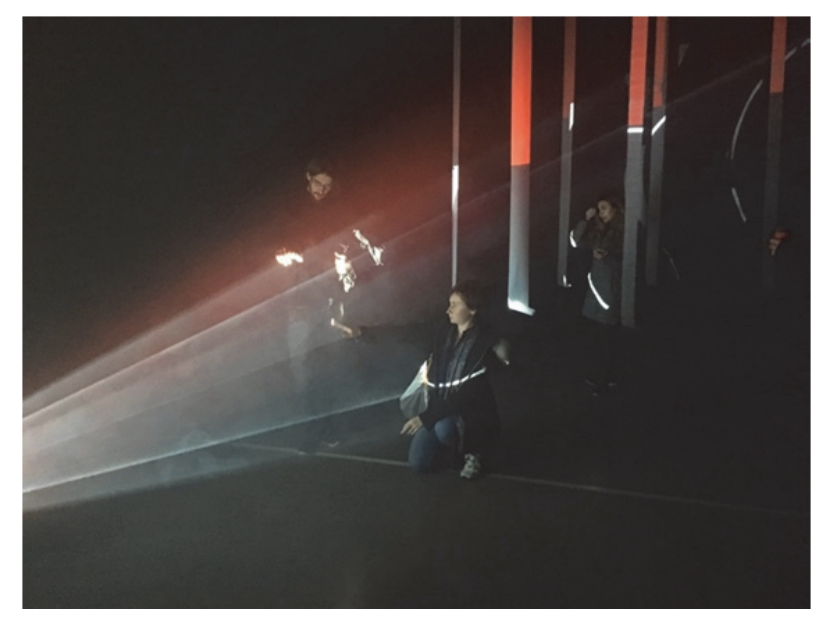

Figure 16: Posing in the light Singing Light 1 (Watkins 2018).

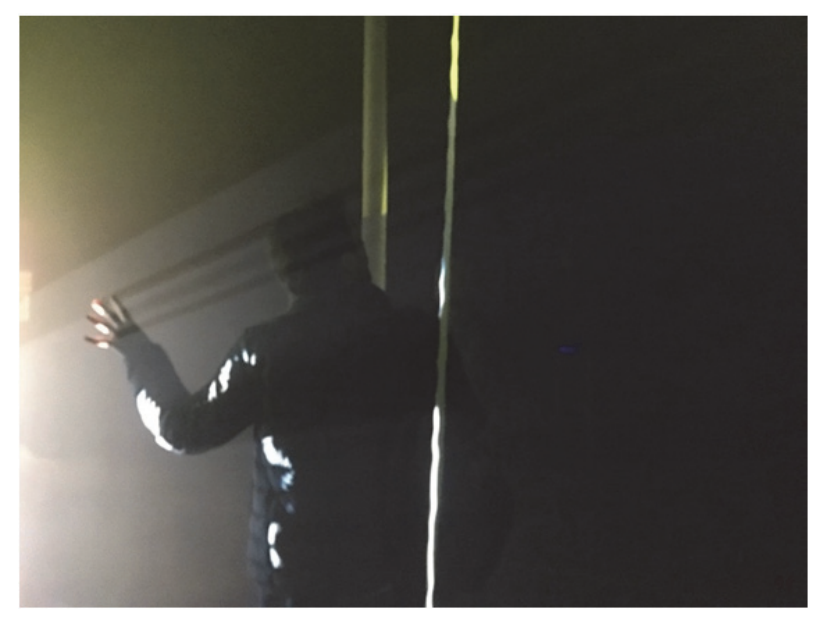

Figure 17: Drawing finger shadows in the light Singing Light 1 (Watkins 2018).

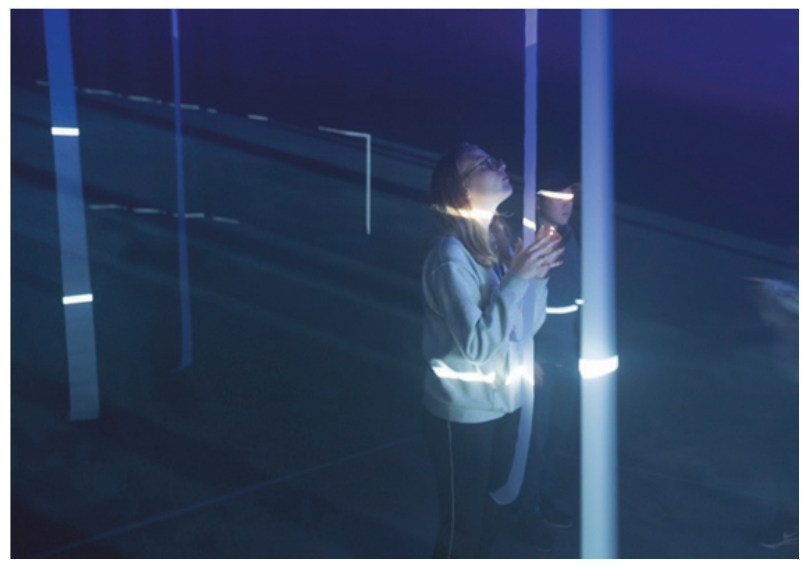

Figure 18: Examining the flags and looking all around the space Singing Light 1 (Watkins 2018).

Overcoming their surprise the participants started to interact: they filmed the light beams took photographs of each other in the light and 'selfies'. As they became more confident some of the spectator-participants interacted with the light, which, in the ever-changing haze looked soft and inviting, touchable. They drew shadow shapes with their fingers, sat in the light, posed in the light, examined the flags and looked all around the space. Spectator-participants talked quietly with each other, becoming quiet when they heard the sung sounds. The intermittent "acousmetre" caused varying degrees of surprise, the spectatorparticipants tended to stop moving and look passively at the animation on the back wall.

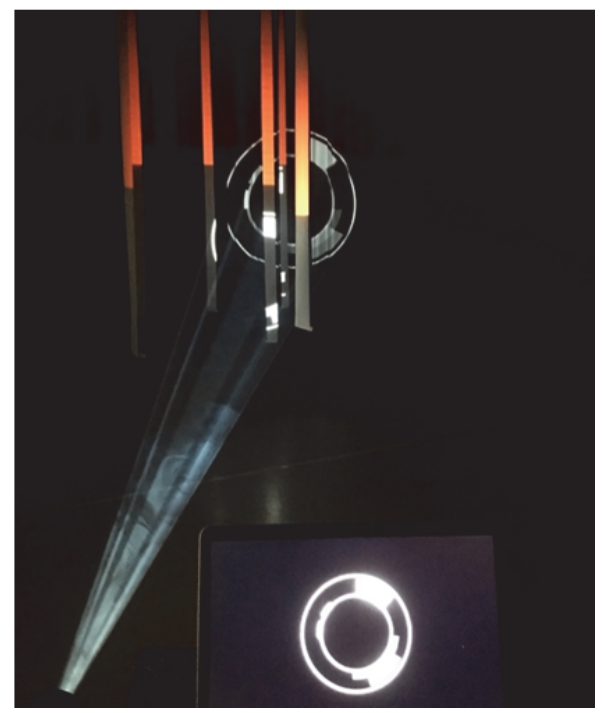

Figure 19: Visible 'workings', the animation that creates the volumetric light Singing Light 1 (Watkins 2018). 
The workings of the display were not hidden. The animations, projectors, flags were all available to be examined. When they reached the end of the path they could see the animation as it was being projected (Figure 19). The spectator-participants were taking part in the SOUND/IMAGE 2018 conference and many were curious to see the details of the workings.

The reaction was overwhelmingly positive. A selection of anonymous comments: "Beautiful", "Meditative", "Lovely", "Mesmerizing", "Light always fascinates". Pleased with 'selfies' in the light: "This is so going straight on Instagram." "Love this" "Wow, it is great to interact with it" "The space is like infinity" "It is very sweet to see people interact with the light." "Amazing illusion of 3D." I noticed that a greater number of spectator-participants resulted in less interaction. When there were twenty spectator-participants in the room one said: "This is a very personal experience-there are too many people to play freely-only the younger ones do." The optimum number seemed to be between two and ten. There was a social awareness of the others in the room, there was a good deal of careful movement so that people could get different views and visually record themselves and each other. Spectator-participants would circle around and come into the light again, rather than block others. It was only when the room was very nearly empty that one spectator-participant cupped her hand around the strong projection beam, irising-down the stream of light at its source, blinking it off for an instant, before releasing the flood of light and illumination.

Singing Light 1 was successful as interactive visual music on several levels. The environment was large enough to allude to the sense of "bigness" that evokes nature the sublime (Griffiths 2008, p.9). Creating an installation in a scale that is large enough to immerse a person is central to exploring different approaches to composing visual music. The scale combined with the darkness immediately identified the space as an immersive space "as somehow separate from the world" (Griffiths 2008, p.2). A truly immersive space does not impose the constraints of fixed-screen media, i.e. it allows spectators to look around freely; duration, position and angle of gaze is not pre-determined by gazing at a screen. As well as affording spectators this freedom, Singing Light 1 was designed to take advantage of being viewed from multiple directions. As stated above, the careful positioning and balancing of the intensity of the coloured and white projections of light, the flags, the choices of surface to receive the projections, the use of flags to allude to planes of depth, all created a multi-planar environment with complex levels-of-depth that was engaging when viewed from any one of multiple viewpoints.
Ideally an immersive space allows the spectatorparticipant to move around the space, meaning that their "viewpoint is no longer static or dynamically linear, as in the film" (Grau 2003, p.16). Spectatorparticipants moved around Singing Light 1. This engendered a more bodily experience, moving into, through, around and out of the projections. This movement made the spectators into participants as their actions changed the experience for the others as well for themselves. As noted above, there was a social awareness, spectator-participants could be seen to give each other room to see different angles, and space to visually record themselves and others. This ethos became part of Singing Light 1. It was inhabited as an experiential piece, as Jordan Belson articulated:

\section{I don't want there to be any ideas connected to my images, and if there are any there, if anybody sees any, those are entirely in the eyes of the beholder [...] Actually, the films are not meant to be explained, analysed, or understood. They are more experiential, more like listening to music (Brougher et al. 2005, p.148)}

Singing Light 1 enriches the "cinematic" with the "pictorial" through engaging the beholder in contemplative looking, inspired by "slow cinema", and the "sculptural" as the beholder can walk around the image and even touch it. This phenomenological approach elicits the fluid perception given to "movement-image" in an almost-still image. The beholder relinks an "empty" image so that it becomes "full" (Deleuze 1992). Singing Light like Anthony Gormley's Blind Light (2007) explores 'real bodies interacting with a conceptually-structured space.' Gormley in (CaigerSmith \& Gormley 2010, p.111). There was a haptic dimension, unlike film on a screen; some spectatorparticipants touched the projection. The projection did not actually touch them back, but their touch cast shadows into the projection (Figure 17) and the haze reacted to their movement. This was engaging and affecting for the spectatorparticipants who touched the projection, and also fascinating for observers; it is so unusual to be able to do more than observe visual images (Figure 18).

Change, for example when one shape morphed into another, caught the attention of spectatorparticipants. However, when the change was imperceptibly slow, for example the rectangle changing height over six minutes, attention mainly stayed with the projected three-dimensional volume. The variation in rate of change influenced the flux from mainly almost-static spectators of visible change-some quickly photographed it-to more participants-moving, and playing with the light-in the imperceptibly changing sections.

Observation of the spectator-participants demonstrated that their experience of immersion in 
Singing Light 1 had similarities to my own experiences of immersion in such installations such as Blind Light and UVA's Momentum (2014), i.e. though one is surrounded and affected by a space that is "other", the experience of critical distance or immersion is not binary but complex and multifaceted. Perception and affect intermingle as Deleuze describes:

\begin{abstract}
[P]henomenology must become the phenomenology of art because the immanence of the lived to a transcendental subject must be expressed in transcendent functions that not only determine experience in general but traverse the lived itself here and now, and are embodied in it by constituting living sensations. The being of sensation, the bloc of percept and affect, will appear as the unity or reversibility of feeling and felt, their intimate intermingling like hands clasped together. (Deleuze \& Guattari 1994, p.178)
\end{abstract}

The spectator-participants demonstrated how one's state flows between being affected and absorbed in the physical present and being mentally stimulated. Physically playing with the light and observing the light, highlights the affect and absorption. Curiosity about the workings of the piece and expressing the desire to create something using light projections themselves highlights the mental stimulation. The affordance of being more deeply immersed, or at a more of a distance and musing, aligns singing Light 1 to "soft fascination".

These findings begin to address a significant gap in the research around composing interactive visual music in the twenty-first century and hopefully visual musicians, artists, animators and performers will find this useful.

\section{REFERENCES}

Adcock, C. E. and Turrell, J. (1990) James Turrell: the art of light and space. University of California Press, Berkeley, US.

Brougher, K., Mattis, O., Museum of Contemporary Art (Los Angeles, Calif.), \& Hirshhorn Museum and Sculpture Garden (eds) (2005) Visual music: synaesthesia in art and music since 1900. Thames \& Hudson, London, UK.

Chion, M., Gorbman, C. and Murch, W. (1994) Audio-vision: sound on screen. Columbia University Press, New York, US.

Deleuze, G. (1992). Cinema. 2. Athlone Press, London, UK
Deleuze, G. and Guattari, F. (1994). What is philosophy?: Columbia University Press, New York, US.

Evans, B. (2005) Foundations of a Visual Music Computer Music Journal, 29(4), 11-24.

Flanagan, M. (2012). 'Slow Cinema': Temporality and Style in Contemporary Art and Experimental Film. University of Exeter, Exeter, UK.

Griffiths, A. (2008). Shivers down your spine: cinema, museums, and the immersive view. Columbia University Press, New York, US.

Guggenheim (2017) James Turrell Exhibition Website.

http://web.guggenheim.org/exhibitions/turrell/ (retrieved 3 July 2017).

Ihde, D. (2007) Listening and voice: phenomenologies of sound (2nd edn.) University of New York Press, Albany, US.

Juslin, P. N. and Laukka, P. (2003) Communication of emotions in vocal expression and music performance: Different channels, same code? Psychological Bulletin, 129(5), 770-814.

Kaplan, S. (1992) The Restorative Environment: Nature and Human Experience. In D. Relf (ed.), The Role of horticulture in human well-being and social development: a national symposium, Arlington, Virginia, US, 19-21 April 1990, 134-142. Timber Press, Portland, OR, US.

Klee, P. and Spiller, J. (1970) Notebooks: Volume 2. G. Wittenborn, New York, US.

Lund, C. and Lund, H. (eds) (2009) Audio visual: on visual music and related media. Arnoldsche Art Publishers, Stuttgart, Germany.

Mackintosh, I. (2003) Architecture, Actor and Audience. Routledge London, UK.

McCall, A. (2014) Artist Talk. In Anthony McCall: Solid Light Films and Other Works (1971-2014). Amsterdam. Vimeo: https://vimeo.com/140631580 (retrieved 25 January 2019).

Merleau-Ponty, M. (2005) Phenomenology of perception. (C. Smith, Trans.). Routledge, London, UK.

Moholy-Nagy, L. (1987) Painting, photography, film. MIT Press. Cambridge, MA, US.

Richter, H. (1952). Easel-Scroll-Film. Magazine of Art, February 1952.

Watkins, J. (2017) An investigation into composing visual music today. Body, Space \& Technology, 16(2). 